\title{
When Cracking the JEE is not Enough
}

Processes of Elimination and Differentiation, from Entry to Placement, in the Indian Institutes of Technology (IITs)

\section{Odile Henry and Mathieu Ferry}

Translator. Renuka George

\section{OpenEdition}

\section{Journals}

\section{Electronic version}

URL: http://journals.openedition.org/samaj/4291

DOI: $10.4000 /$ samaj.4291

ISSN: $1960-6060$

Publisher

Association pour la recherche sur l'Asie du Sud (ARAS)

\section{Electronic reference}

Odile Henry and Mathieu Ferry, "When Cracking the JEE is not Enough », South Asia Multidisciplinary Academic Journal [Online], 15 | 2017, Online since 22 March 2017, connection on 19 April 2019. URL: http://journals.openedition.org/samaj/4291 ; DOI : 10.4000/samaj.4291

This text was automatically generated on 19 April 2019

\section{(c) $(1)$}

This work is licensed under a Creative Commons Attribution-NonCommercial-NoDerivatives 4.0 International License. 


\section{When Cracking the JEE is not Enough}

Processes of Elimination and Differentiation, from Entry to Placement, in the Indian Institutes of Technology (IITs)

\section{Odile Henry and Mathieu Ferry}

Translation : Renuka George

We thank Yoann Demoli (Associate Professor, UVSQ, Laboratoire Printemps) for his advice on econometric models.

\section{Introduction}

1 Since Independence engineering studies have been seen as a force capable of transforming Indian society, with advanced technology occupying a central position in the development model. Hence the Indian Institutes of Technology (IITs) in particular embody the values of modern India promoted by the political elite. ${ }^{1}$ Exempted from the application of reservation policies at first, the IITs were long perceived as meritocratic elite institutions released from contingencies related to caste and their political exploitation. The success of IIT graduates in the US computer industry in the 1980s (Lardinois 2014) and the liberalization of the Indian economy in the 1990s tend to make IIT a "brand" associated with Indian global competitiveness and the values of a private sector "disembedded from the social and political spheres" (Subramanian, 2015).

2 However, with the introduction of quotas for the Scheduled Castes (SCs) and Scheduled Tribes (STs) ${ }^{2}$ in 1973, then a new category of reservations for the Other Backward Classes $(\mathrm{OBCs})^{3}$ in $2008,49.5 \%$ of seats at IIT are now "reserved," as compared with only $22.5 \%$ before 2008. Some former students, products of this institution that was marked by a very strong social homogeneity when it was first conceived, see the introduction of quotas as a threat to the meritocratic spirit of the IITs. They believe the "marked down" admission of these new students has weakened the IIT "brand." In contrast with these nostalgic observations on the lost purity of the elite, the discourse pronounced within the 
institution by a section of the professional corps tends to strongly defend the meritocratic nature of the IIT. Thus there is supposed to be a high correlation between the level of academic achievement, admission to a stream and an IIT (which are also hierarchized) and placement on the job market: the best students are supposedly admitted to the most selective streams and go on to secure jobs that are both better paid and offer better prospects, in career terms.

3 As the object of differing evaluations, the meritocratic model embodied by the IITs today should be empirically explored. Are the IITs, and particularly their "undergraduate programs," 4 a vehicle for social mobility based solely on the students' skills, as they claim? This vulgate, spread by the media, which students and their families largely believe, deserves to be questioned.

4 A certain number of studies carried out on India in the 1970s and 80s tried to assess the value of the institutions encouraged by the Constitution of 1947, and studied the connections between education, the distribution of power within society and the circulation of elites (Krishna Kumar 1985; Rajagopalan and Singh 1968; King 1970). These works tend to show that positions within the Indian elite, particularly the bureaucratic and economic elite, are the monopoly of the upper castes, and that so-called merit based selection corresponds largely to selection based on social background. C. Rajagopalan and Jaspal Singh conclude that the IITs made a very low contribution to phenomena of social mobility in the 1960s and 70s. Although they are not free of a certain normativity, the conclusions of a more recent work underscore the under-representation of the most dominated categories within the IITs, in terms of caste, class, gender and religion (Roli and Kapur 2009). With the introduction of reservations for the OBCs, and the high increase in the number of students admitted to IIT $^{5}$ as a consequence of this, do we currently see the rise within these elite schools of "new" social groups, or groups that were formerly marginalized? Or, on the contrary, has there been a reinforcement of the positions of power occupied by members of the former elite? Further, to what extent do the IITs contribute to a relative opening up of the Indian elite, for example by encouraging access for the elite of these populations dominated in terms of caste or gender.

5 The results of the research presented here aim to provide a general documentation of the role IITs play in the process of reproduction of the social order, particularly their contribution to the reproduction of the Indian elite. They provide empirical elements and statistical analyses that enable an identification of the social functions endorsed by these schools, described as schools of excellence. They thus highlight the processes by which the IITs both continually and differentially eliminate students from the dominated groups (particularly those belonging to the SC and ST categories), and contribute to a strongly differentiated return, hence the social value, of academic titles on the job market. Thus, although they are formally identical, the academic titles obtained by SC and ST students, are globally less productive. Far from giving in to a functionalism that would endow the institution with an intentionality, the sociological reasoning adopted here attempts, on the contrary, to reconstitute the various institutional processes, which taken together, contribute to "creating" these statistical trends.

6 The statistical results presented in this article were produced, as we will see, by recoding and processing a group of numerical data, produced by the institution for its own practical needs. Gathered over the course of a long field study (December 2014 to December 2016) conducted at one of the IITs $^{6}$ these institutional data all show a 
breakdown of the student population by admission status, although in their statements the people interviewed-both professors and students-agree that social differences (of caste, class, gender, religion) lose their pertinence once a student is admitted to the campus. These administrative categories distinguish students admitted on quotas (SCs, STs, OBCs) from the "General" students (called GENs or even "Merit Based Admission" students), that is to say students who did not benefit from the reservation policy. Carrying out a socio-genesis of the idea of meritocracy in India, Satish Deshpande's (2013) work shows how, from the 1930s onwards, a new norm of "castelessness" emerges and, with the application of reservation policies, is practically embodied in this so called "General" category. Such an appellation tends to erase all caste characteristics leaving only merit. This conforms to the historical process by means of which the dominant castes in India have gradually transformed their illegitimate inherited capital (social status related to caste) into a modern capital (access to property, education and modern professions). At the end of this long process, the collective identity of the GENs is marked by the qualification achieved, and caste (rendered invisible) is erased, while the collective identity of the lower castes remains primarily marked by caste (rendered hyper visible), and the acquired qualifications remain secondary. The author underscores the fact that with the "conflagration" generated by the Mandal Commission in 1990 and the introduction of quotas for OBCs, the "GEN" category becomes a euphemism for a small, relatively homogenous social group-the members of the privileged castes-and a convenient appellation that allows the members of these castes to see themselves (and to be seen) as "modern," or casteless, released from any caste association. Such a sociogenesis very convincingly reveals the processes of collective amnesia involved in the constitution of the national history. Thus, the institutional history of Indian modernity is written by strongly denying certain grey areas: on the one hand the history of the processes of normalizing the elite and the reconversion of forms of inherited capital. On the other hand, that of the processes that made caste identity, which along with the reservation policy now constitutes a major resource for the dominated groups, something outdated, a block to the democratization process and hence illegitimate.

7 Within the conceptual framework forged by Deshpande, Subramanian's (2015) research highlights the important role the IITs historically played in this process of converting an inherited caste capital into an acquired modernistic capital. Nonetheless, while these works underscore the historical unconscious that inhabits the institution and the administrative categories it produces and reproduces, they say nothing about the institutional work of aggregation and segregation of populations over the course of which these administrative categories are continually updated. In addition, while they draw attention to the processes of assigning identities, they brush aside the fact that the forms of segregation applied within IITs go hand in hand with ongoing and often masked forms of exclusion of students belonging to the dominated populations. Lastly, based on analyses of discourses (official speeches or interviews) or in other words, representations of the world, the analyses presented in these works deserve to be related to the objective reality of the practices. That is to say, on the one hand, the statistical trend that reveals there is a higher probability of students registered on the general list fully benefitting from the educational capital they acquire at IIT, and hence representing the only legitimate title holders this institution produces. And on the other hand, the concrete daily mechanisms that create this trend are brought out. It would seem that it is only by revealing the correspondences between objective social structures and mental (or cognitive) structures that research gives itself a chance to denaturalize the institution, the social hierarchies it 
produces, and the principles of hierachization that invest these hierarchies with their strength. (Bourdieu [1989] 1996:1-6).

To clarify the presentation we will distinguish between various mechanisms which contribute to the creation of the statistical trend. We will start by explaining the data collection methods and the operations involved in the processing of this material. We will go on to examine the work done by the institution to produce administrative categories that fulfil its needs, that is to say the concrete operations of grouping and differentiation required for the production of taxonomies. The third part will deal with the mechanisms of male and female student selection that take place even before the student joins IITL, during a little known phase of the national JEE competition, in which the students have to rank and record their choices. The last two sections will examine the processes of differential elimination and differentiation in the social value of the degrees.

\section{Survey methods, data gathered and data processing}

Our survey is based on a long fieldwork study carried out at IITL. During this fieldwork, we conducted a number of ethnographic observations (11 ten-day fieldwork sessions) and 62 interviews with professors, students and some former students. During the first year of this fieldwork, we were able to gather a certain amount of data on the student population produced by the institution (see infra), which we had to enter, encode and process. ${ }^{7}$ Nonetheless, in order to process this data, which is key to an understanding of the institutional policy, we first had to understand the internal logic that led to its production, and hence carry out further interviews.

For the moment we have chosen to limit the surveyed population to undergraduates, that is to say those who were admitted to IITL after passing the JEE. There are a variety of reasons for this choice: apart from reasons of feasibility, we want to work on those who are internally considered the "cream of the elite," as the JEE embodies a model of hyperselectivity and incorruptibility.

Three types of data were collected:

12 First, national data from the JEE 2011, that is to say the official (public) report and different databases related to the 13,196 students who qualified for admission, 9,627 of whom were finally admitted. These data allow us to correlate the ranks obtained in the exam-differentiating the ranks of the students accepted under the Common Merit List and those who were admitted under the quota system-and the stream and the IIT where these students registered. The students who obtained the highest ranks in the JEE tend to "choose" the most highly-rated branches of knowledge (grouped under departments in IIT terminology). The ranking of the departments is partly linked, as we will confirm below, to the placement rate on the job market and the salaries offered.

Then we have the data produced by the Dean of Academic Affairs' office (IITL), the "Roll list of Undergraduate Students," a thick, printed document that shows the distribution of the students by degree and department chosen for each semester of the university year. This office provided us with data compiled over the last 10 years (2004-2005 to 20142015). These lists specify the students' admission status, their gender and they also show the number of physically handicapped ( $\mathrm{PH}$ ) students. We chose to process this administrative data in a manner that allowed us to reconstruct the seven classes of students who joined IIT between 2004 and 2010 (and graduated between 2008 and 2015), 
to follow the cohorts over the 4 to 5 years of their studies and to observe the failure/ dropout and repeat rate.

In order to evaluate the failure/dropout rate for each class, we decided to focus on the whole class admitted to BTech and to compare the number of students registered in the first year (semester 1) with the number of students registered in the fourth year (semester 8). The difference between these two figures represents the number of failures/ dropouts. Finally, we related the number of failures/dropouts to the initial size of each class; this failure/dropout rate constitutes the first academic success indicator. To evaluate the repeat rate for each class we calculated the number of students present in semester 9 for the students doing a BTech and the students present in semester 11 for the students doing a DD or an Int MSc, as these figures were the highest. When we relate them to the number of students present during the final semester of each program, we hence obtain the repeat rate for each program.

Lastly, data produced by the Student Placement Office, SPO, provides information about the 1,090 students registered with this administrative department in 2014-2015. It collects information about academic success (the CPI, cumulative performance index, an academic score updated every semester on the basis of the marks obtained since the beginning of the course), job placement (placed, not placed, position occupied, economic sector and salary range), the degree and department and lastly the student's status (GEN/ $\mathrm{SC} / \mathrm{ST} / \mathrm{OBC}$ ). This database covers all the students in all the streams offered at IITL (that is to say, the UG and PG programs), which in the long term will allow us to carry out a comparison.

These three types of data are not completely homogeneous due to the reform of the undergraduate program in 2011. Until 2011, students admitted to IITL (UG program) had a choice between three types of degrees: Bachelor of Technology (BTech in 4 years), Dual Degree (DD, Bachelor and Master of Technology in 5 years) or Master of Integrated science (MSc Int in 5 years). Since 2011, the Dual Degree (DD) and the Master of Science Integrated (Int. MSc) - degrees created in 2001 and 1972-were abolished by government decision. The Master of Science has been transformed into a Bachelor of Science (BSc) open to students admitted through the JEE. The Dual Degree remains a course reserved for students admitted under the JEE, but now the option of prolonging the course by a year is taken in the third academic year and is dependent on an internal IIT selection process.

\section{The creation of taxonomies}

17 Although caste is to a large extent denied in the official discourses on the institution the admission status (that includes numerous sub-castes, castes or jati and meta-castes) ${ }^{8}$ is omnipresent (as is the degree the person is working towards and their branch or discipline) in the data regularly produced by the institution on itself. This is not the case of gender, however, a category that does not systematically appear in these data books.

One example of how the institution produces and reproduces these categories is the rankings that are established on the basis of the Joint Entrance Examination Advanced (JEE), which is a means of selecting "undergraduates." This highly selective ${ }^{9}$ national (pan-Indian) examination contributes to substantiating the ideal of the IITs' independence and the meritocratic values it claims to represent, distinguishing it from 
other engineering colleges, which are supposedly more exposed to social pressures. The very proceedings of the examination seem to guarantee that meritocratic values are respected: the disciplines selected for the test (mathematics, physics and chemistry) are precisely those which are the least open to various kinds of inherited "capital" (in 1988, the English test paper was removed and from 1990 onwards the exam could be conducted in English and in 13 regional languages, [Kelkar 2013]) and the standardization of the marking system significantly limits the possible consequences of the examiners' subjectivity. After the examination students are ranked according to their grade and their admission status.

19 A nuanced description of the manner in which this competitive examination takes place is required in order to grasp the institutional stakes involved in this type of classification. We will look at the case of the 2011 JEE. The 15 IITs and the Indian School of Mines Dhanbad, had a total of 9,627 available seats, $50.5 \%$ of which were attributed to students who do not claim reservation status (GENs) or choose not to benefit from it, ${ }^{10}$ and $49.5 \%$ were, in principle, allocated to students admitted on the quota basis. In order to fill the seats, a "Common Merit List" (CML) is created. ${ }^{11}$ Then, the score obtained by the last person admitted from the Common merit list represents the cut-off mark. Students whose results are lower than this mark benefit from positive discrimination measures (relaxed standards) if they are in possession of a certificate stating they belong to a reserved category and have registered for the examination as a member of one of these categories. Thus, OBC students can be admitted on condition their results are no lower than $10 \%$ below the cut off mark, while SCs and STs can be admitted on condition their results are no lower than $50 \%$ less than the cut off mark.

During the qualification process four rankings are created. The general ranking groups students qualified on the CML (the GENs). The OBC, SC, ST lists include students who register for the competitive examination as members of a particular caste. Contrary to the idea that all the students who belong to the reserved categories would benefit from a marked down competitive exam ('relaxed standards'), we note that these three lists include both some students who qualify on the CML-this is the case for $59.4 \%$ of OBCs, $6.3 \%$ of SCs and $5.1 \%$ of STs-and students who benefit from a score below the cut off mark. It is surprising that the minority students who qualify on the CML are still almost always admitted to reserved seats and then counted on the basis of this admission status. According to the JEE examination board spokespersons, this procedure is in their interest: with an equal score, an $\mathrm{OBC}, \mathrm{SC}$ or ST student will be in a far more favorable rank in his category list than on the general list and will hence have access to a wider range of choices. But it is also true that such a procedure ensures as well that students from the minority groups who registered for the competitive examination under these categories, and obtained scores comparable to the GENs do not occupy the seats the GEN are "entitled" to. Admission status as a constructed category hence tends to amalgamate student populations whose educational performances are highly variable. Such institutional logics which manufacture homogenous groups based only on admission status have clear consequences, as, when they introduce themselves the students are required to disclose their rank in the competitive exam, and thus the category under which they were admitted.

21 Although those responsible for the competitive examination underscore the fact that the examination is entirely computerized, both in terms of the calculation of scores and ranks as well as the attribution of seats (value judgments are believed to have been 
completely eliminated from the examination), the way the JEE is organized contributes to differentiating certain groups within the student population, notably students who qualify but are not admitted due to a shortage of seats, a majority of GENs and students admitted with lower marks. ${ }^{12}$ These disclosed data seem to be a boon for research dealing with the evaluation of Affirmative Action policies ${ }^{13}$ as they provide certain empirical foundations for categories constructed for research purposes: the displaced and displacing groups. ${ }^{14}$ But such social constructions also fuel the resentment felt by a number of students who do not come under any of the quotas, as one can see both in the interview excerpt below and the stereotyped images of the admission status categories that circulate widely on social networks (Figure 1):

"It's very common for SCs / STs, accustomed to having everything without working, to claim that they have bad grades at IIT because they are discriminated against because teachers do not like them, etc. Their delay in basic skills is so great that to succeed they would have to work much more ... Those students who think everything is owed to them may experience a kind of segregation on campus, because some GENs have friends that have not been received at IIT with much better results" says Adit, a final year Dual Degree student in Civil Engineering, from the Koshta community in Madhya Pradesh. This community is listed as $\mathrm{OBC}$ but Adit was admitted through the general list because his parents' income is above the limit. Adit says his family is "Sanskritized": his grandfather is illiterate, his father, a Master of Technology from a "small" Jabalpur (MP) college is a professor of environmental engineering at the National Institute of Technology (NIT) in Bhopal and his mother, he said, works as an executive secretary, something that is extremely rare in this community. ${ }^{15}$

Figure 1 - Picture circulating on Facebook and forwarded to us by an ST student.

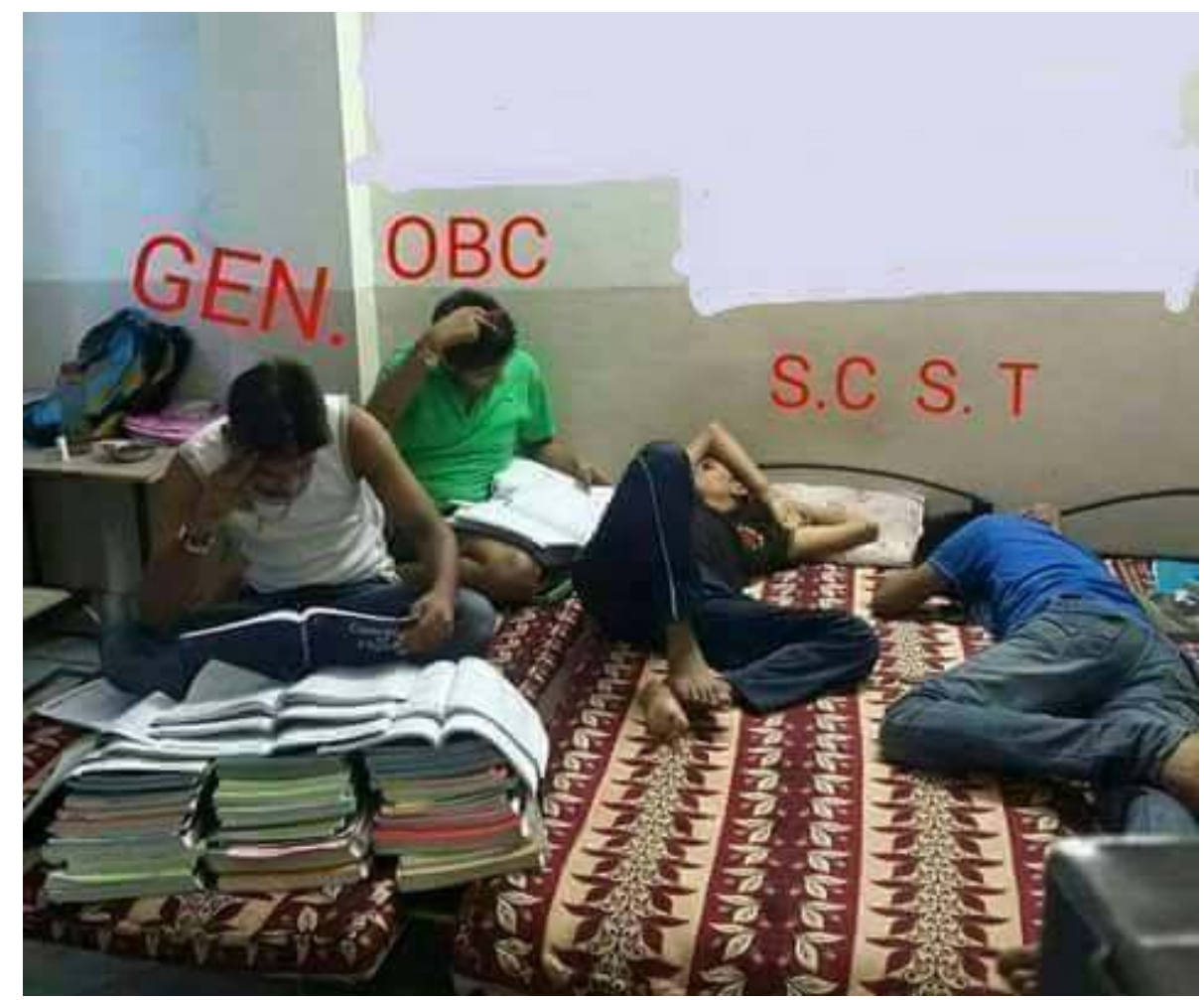




\section{the detriment of caste, and inversely to the identity of the students from the dominated groups being marked by caste to the detriment of the achieved educational qualification, are not only based on discourse, but as we just saw, they draw their efficacy from unquestioned social categories, employed in the most banal administrative practices. The production of these categories is the fruit of a specific effort and fulfils institutional needs. Integrated into the very core of the cognitive structures transmitted by the institution, administrative categories make a major contribution to structuring perceptions of reality and, in this way, become a powerful marker of social identities. The analysis we have sketched here of the social conditions under which they are produced is an integral part of the exercise of reflexivity the social sciences must subject themselves to (Bourdieu 2004) and as such, it constitutes an indispensable precondition to statistical analyses of data constructed on the basis of these taxonomies. \\ "Students' choices": a final phase of the selection process}

he mechanisms that contribute to the GEN students' identity being marked by merit to

The ranking in the national examination (JEE advanced) determines to a certain extent the possibility of joining one of the IITs, a program, and a department of study, with each of these entities occupying a position within a hierarchy. ${ }^{16}$ Now, the process by which the available places are attributed during the last phase of the JEE is both little known and highly complex. In a way, we can say that this process constitutes a final stage of the selection process, no aspect of which is left to chance. Many of the students interviewed described this major step, and we compared their explanations with the JEE 2011 data we had access to. The qualifying students enter an unlimited number of choices on an online platform, but at least one of these choices must be within the possible options associated with the rank the student has obtained. At the end of the process, that is to say after three rounds during which the algorithm offers the available places, first to the students with the highest ranks on each of the lists. A total of 9,311 candidates are accepted, which means that about $29.4 \%$ of the 13,196 qualifying students will not be able to join the institution. ${ }^{17}$ In $2011,35.8 \%$ of the qualifying GENs were not admitted as compared to $19.3 \%$ of the qualifying OBCs, $29.3 \%$ of the SCs and $11.6 \%$ of the STs. ${ }^{18}$

These figures describe different realities: the correspondence between the number of qualifying candidates and the number of seats available is the least advantageous for students who do not come under any of the quotas, but for the OBCs, SCs and STs, the correspondence is better balanced. This leads us to believe that when GENs have a low position in the ranking, they prefer to choose a different academic path or they maintain their application but do not gain admission to an IIT. On the contrary, OBCs, SCs and STs seem more often to have expressed choices that cannot realistically be fulfilled given their ranking in the exam and they are eliminated for this reason.

Thus, the formulation of choices is a very delicate matter. Many of the students interviewed stressed the crucial importance of advice provided by people close to them (family, neighbors, teachers, etc.) at this stage of the examination to figure out these multiple hierarchies: what is a prestigious branch? What is a "good" IIT? And is it better to request a prestigious branch in a lower ranked IIT or the contrary? The lack of social and/or cultural capital, therefore of familiarity with the administrative rules and with

South Asia Multidisciplinary Academic Journal, 15 | 2017 
the dual hierarchy at work in the IITs and their departments, leads to a certain level of failure every year in obtaining a place at an IIT.

"Errors" of perception regarding the options available seem to be more commonly made by students admitted under the quota system. Without access to relevant information, these students have a strong tendency to follow the choices made by students who obtained the same rankings in previous years, ${ }^{19}$ even though the scores and places never correspond exactly from one year to the next. These "ill-informed" students may thus request a place well above their rank or not explore all the options available to them. In fact, the only means of ensuring a place at an IIT is to ask for a place well below that which one's rank would permit access to. This is the case of some of the women who "choose" a department that has a low rank and a reputation for being a "women's" department (bioengineering, for example), while they could gain access to more prestigious departments, but which are also seen as essentially “men's" departments.

Inversely, the best-informed students can set up fairly sophisticated compensatory strategies. Thus Subha ( $4^{\text {th }}$ year, Master of Technology, Mechanical, IITL), a student admitted on the general list, did not get a very high rank in the JEE, but she wanted to join a core branch at one of the 7 oldest IITs. Now she was only allowed to apply for the scientific courses, which she rejected. On the advice of people close to her (her father is an orthopedist, her mother a housewife who holds a doctorate in botany, and she has a cousin who was a student at IITL while she was preparing for the entrance examination), she opted for a BTech in Mechanical engineering, a core branch, but not very open to girls, in a more recent IIT, but located in the same state as IITL. As she had been informed of the close links between the two IITs, after her BTech, she applied to and almost automatically gained admission to the Mechanical engineering department for a postgraduate program at IITL.

\section{Differential elimination of students}

At IITL can one identify certain processes of relegation or elimination that would more specifically target certain categories of students? Our analysis tends to show that the admission status does not seem to be a discriminating factor in the distribution of students within the hierarchized streams,$^{20}$ with each stream more or less respecting the quota policy. SC and ST students are nonetheless more present in the most profitable streams in terms of professional insertion, that is to say the engineering streams, and these are also the most sought after and the most prestigious. ${ }^{21}$ However, with the increase in the number of SC students admitted, we note that from 2008 onwards, like the GENs, these students are forced to occupy seats in the longer and less appreciated scientific streams. ${ }^{22}$ The SC students interviewed more often mention that when they choose the scientific streams, they are more interested in disciplines (like economics, sociology or political science) that lead to professions related to an analysis of society, with a perspective of social reform, particularly in terms of education. Lastly, girls, who in 2014-2015 represent only $7.5 \%$ of all first year students registered in the undergraduate program, are more often relegated to the scientific streams or to the least well-classified engineering departments. ${ }^{23}$ Here our results differ from Sreelekha Nair's conclusions (Nair 2012) that associate the progress in the representation of women in engineering training with the development of new disciplines (Computer Science, Electrical Engineering, Electronics and Communication) that are less committed than 
others (mechanical or aerospace) to virile values, and thus more open to women. On the contrary, in the elite program of an elite school such as IITL, girls are systematically under-represented in the disciplines considered the most prestigious.

While the process of relegation to the less prestigious streams seems essentially to involve female students, what is the situation with regard to the elimination process? The quota policy for entry to an undergraduate programme is globally respected at IITL ${ }^{24}$ but what is the situation at the end of the program? Do students from the dominated groups have equal chances of obtaining their degree from IITL?

31 Two indicators allowed us to measure the students rates of academic success. On the one hand, the failure (or drop out) rate and the repeat reate were calculated by processing the cohorts for 7 class years (2004 to 2010). On the other hand, the academic score students obtain in their final semester, or the "Cumulative Performance Index" (CPI), which is the average of the marks obtained since the beginning of their studies at IIT. ${ }^{25}$

Our results both suport and confirm the earlier commentaries on ST and ST student failure at IITs. ${ }^{26}$ Thus, while 3,4\% of all students fail or drop out, the failure/dropout rate in BTech is higher for SCs $(9.9 \%)$ and STs (7.7 \%) than for GENs (2\%), whereas the failure/ dropout rate for OBCs is lower (1.3\%). As for the repeat rate in BTech (11.1\% for all students), it is higher for all students admitted on quota seats than for GENs: $26.3 \%$ for SCs, $34 \%$ for STs and $8.8 \%$ for OBCs versus $5.9 \%$ for GENs. The Dual Degree and Integrated Master's confirm these trends with some variations. We therefore assert that academic success is overall lower for SCs and STs than it is for GENs and OBCs.

The analysis of the distribution of the "Cumulative Performance index" (CPI) by admission status further reinforces these results. Indeed, figure 3 displays a projection of the densities of CPI distribution by admission status. ${ }^{27}$ The density peaks (or the modes) are in the following ascending order: STs, SCs, OBCs and GENs. While these curves outline differences in academic success between categories, the spreads also highlight the heterogeneity of grades in each of the categories: the STs grade distribution is the most uniform (the peak form is more strongly accentuated). 
Figure 3 - Density plot of CPI marks by caste category (source: SPO)

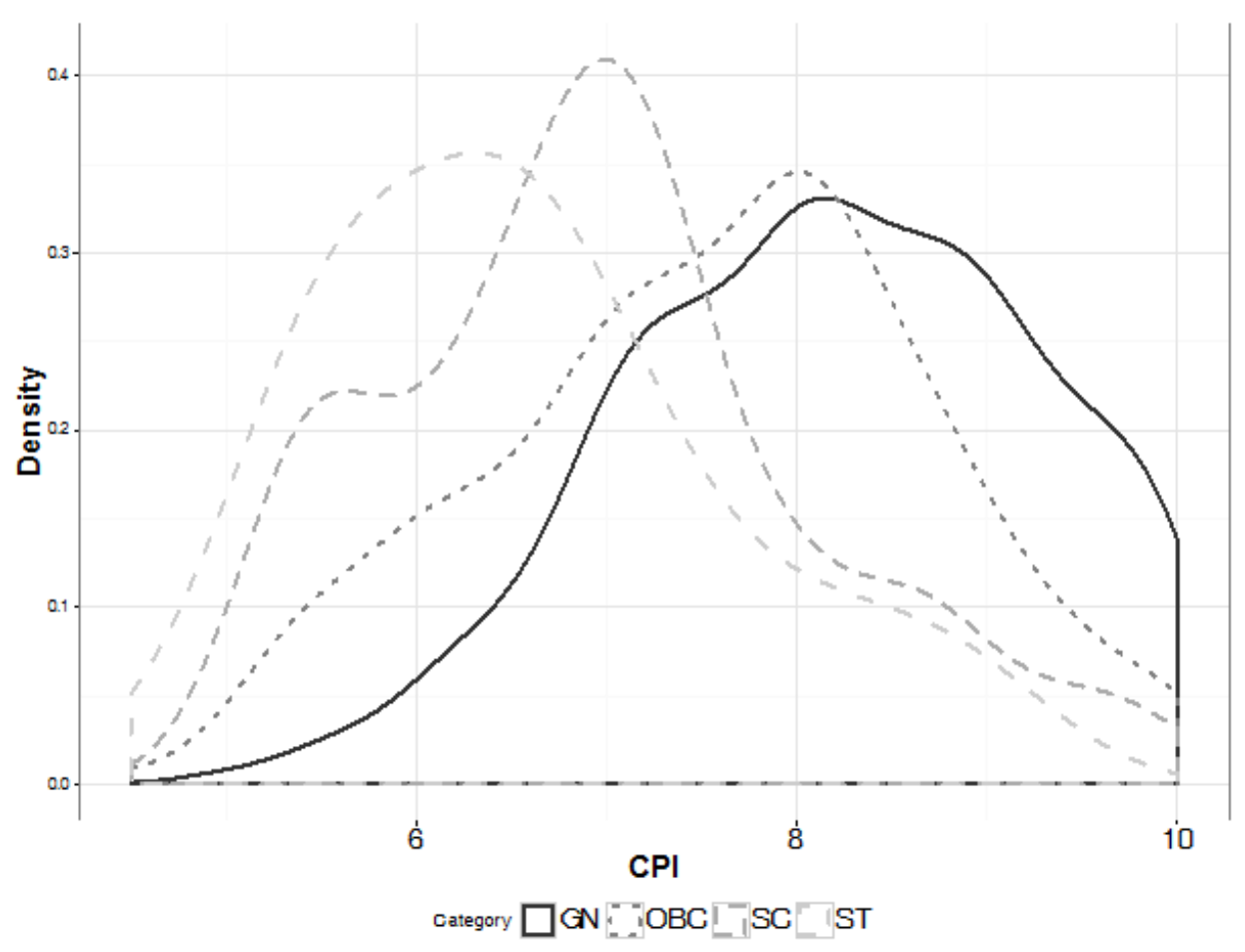

The differential elimination of SC and ST students and the longer duration of their studies contrasts with the girls' academic success. As we know, a large number of them obtained low ranks in the JEE, so they also-but to a lesser degree-have a lower academic level when they join IIT. Thus although the failure/dropout rate is the same for girls and boys (3.1\%), girls repeat less often than boys: $11.2 \%$ of boys as against $9.4 \%$ of girls in BTech. This trend is clearly enhanced for five-year programs: while $12.1 \%$ of boys have repeated at some point in their course, no girl has.

Several hypotheses can be suggested to interpret these results. The SC and ST students' lower level of success is partially the product of academic inequalities at the outset, and the lack of institutional initiatives to correct these inequalities.

Thus the interviews show that SC or ST students who face academic difficulties (which lead, for example, to their names appearing on the "warning list" ${ }^{28}$ ) most often belong to sparsely-educated and poor families (mainly agrarian families) and they are hence the first generation to gain access to higher education. Most of them attended government, Hindi medium, primary and secondary schools, and their parents do not speak English. When they are brutally plunged into an academic world where English is the working language, lectures and classes with over 100 students the norm, and anonymity the rule, all of this reinforces the great difficulty they have in assimilating the teachings. ${ }^{29} \mathrm{In}$ addition, some, who did not have sufficient economic resources, did not attend coaching centers. For example Pradeep, an ST student registered in his 5th year of a Bachelor's degree (Material Science and Engineering, IITL), clearly states it is only on arrival at the campus that the student discovers he does not have the tools to memorize information and work quickly, nor has he acquired the habit early on of working under the stressful conditions (competition and continual evaluation) prevalent in today's educational institutions. All these are techniques the majority of the other students have acquired at 
coaching centers. Abrupt changes in the rules of the game can also explain the differential elimination of students from the minority groups. Thus 73 students (31 STs, $23 \mathrm{SCs}$ and $8 \mathrm{OBCs}$ ) registered in the first year (UG program) were expelled from IIT Roorkee in July 2015, in the middle of the summer holidays. In this specific case it was due to the combination of the marking system or the relative marks ${ }^{30}$ that automatically lowers the CPIs of students whose results are below the class average, and the brutal application of an arbitrarily adopted rule. During the summer, the CPI required in order to register in second year was suddenly raised from 4 to 5 , but the students had not been informed of this when they began their studies, and this explains these massive expulsions (Mandal et al. 2015).

The survey conducted on the campus by a team of researchers brought to light a number of measures that contribute to eliminating the academically-weakest students. Underscoring the disdain with which the IIT Roorke management treated the judgment of a similar case at IIT Delhi, the Fact Finding Report lists the lack of support mechanisms that would give the academically-weakest students real means to progress: irrelevance of the English bridging courses to practically prepare the students for the academic work demanded by IIT, lack of language laboratories, lack of an orientation program that clearly explains to students the rules and functioning of the institution as the time of their admission to IIT, lack of pedagogical support that had been promised by the institution (English language classes, summer coaching classes, slow tracking program), ${ }^{31}$ dysfunctional SC/ST cell, a support structure for students admitted on the quota basis that exists only on paper. This report also underscores other factors that contribute to eliminating students admitted on the quota basis such as the very high registration fee demanded to retake a test, ${ }^{32}$ the experience of discrimination the SC and ST students are subjected to by the professors or the "senior students" responsible for mentorship, ${ }^{33}$ and the non-application of the reservation policy to the professional body. ${ }^{34}$

An analysis of the rationales of sociability on the campus sheds light on another feature of the students' academic trajectories and contributes to explaining the fact that some of those admitted with a low score manage to catch up, while others remain at the bottom of the class. An observation of social life on the campus, and particularly of the sporting and cultural practices, reveals the rationales behind the constitution of student groups on the basis of caste and class. Thus, Abishek ( $3^{\text {rd }}$ year, BTech, Chemical Engineering, IITL) states that the students are divided into two main groups: the GEN group, that includes a few $\mathrm{OBC} / \mathrm{SC} / \mathrm{ST}$ s includes "those who come from cities and share a certain number of dominant social properties: they speak good English, they know how to organize shows, have oratorical skills, and have dispositions for literary questions." On the other side, the SC/ST group includes students from rural areas, little attracted to leisure activities (except the most popular sports like cricket or badminton), who speak English badly and have mediocre academic results. Although there are groups based on regional belonging, they seem to exist with this dominant division "Students do not expect much from the profs, adds Abishek. People learn from their peer circles so group segregation hence has obvious effects."

This observation confirms the analyses carried out at IITM (Subramanian, 2015): with the creation of quotas for the OBCs, GENs increasingly tend to function as a separate entity and to avoid any kind of association with lower status groups. The theoretical model developed by Norbert Elias (Elias and Scotson 1965) seems to be pertinent here: everything occurs as if the GEN students successfully claim a collective identity 
constructed along the lines of the "minority of the best" model, a merit-based minority, into which they attempt to assimilate students from reserved categories admitted "on the basis of merit." In contrast, students admitted on the basis of quotas, the SCs and STs in particular, are assigned a collective identity constructed on the basis of the "minority of the worst" model. ${ }^{35}$ Thus when an upper caste (GEN) student has bad results, "it's because he/she is too busy having fun" while a student admitted on the reserved quota's bad results are interpreted as the result of intellectual shortcomings (Subramanian 2015).

This oppositional structure deserves a specific analysis, questioning, for example, the social gradations that exist within both groups as well as the price to be paid to be included in the community of the best. ${ }^{36}$ Thus Pradeep, an ST student, (5th year BTech, Material Science and Engineering, IITL) finds himself in a situation of academic failure in his first years at IITL and is threatened with expulsion. Shifting out of his isolation, at this late stage he manages to join a group of friends ( 3 are OBCs and the fourth is a GEN) whose academic level is higher than his own. He describes this group of students as average and fairly introverted. Pradeep's inclusion in the group goes hand in hand with an improvement in his performance: his CPI rises from 3.2 in the first year to 4.6 at the beginning of the fifth year. Fairly good at English and interested in the social sciences, Pradeep helps his friends (one of whom is from a Hindi medium school) to prepare for the compulsory subject exams, generally of little interest to the engineering students, although they are difficult as they require a mastery over literary English. In return, his friends help him fill his enormous gaps in math.

The price to be paid for such inclusion, which is also a transgression of the boundaries of the group of origin, varies depending on the students' social properties. Sabeena, a final year Bachelor's degree student (Electrical Engineering), first said she comes from the Meena community (Scheduled Tribe in the state of Rajasthan) before correcting herself and asking me "to put Brahmin instead" as she appeared for, and passed, the JEE on the Common Merit List and did not take advantage of the quota policy. It was as if the fact of being included among the Common Merit List GENs and in the community of the best meant she was automatically marked as a member of the "upper castes." She adopts this group's cultural norms all the more easily as she comes from a wealthy urban family. Nonetheless, the interviews with girls admitted under the quota system (SCs or STs) tend to show that they are more easily included "in the Gen group." One of them explains that "girls are a rare resource on the campus, so they are coveted in the upper-class student circles." This is certainly one of the factors that can explain the girls' exemplary academic success. ${ }^{37}$

41 Inversely, Amit (BTech Computer Sciences and Engineering, Batch 2005, IITL, currently a $\mathrm{PhD}$ student in economics at JNU) pays a high price for the quota policy under which he was admitted. From Bihar, his father belongs to a very poor family: he is a cashier at a bank and the only one of his brothers to have found a "good job." Very isolated as an SC student right from the beginning of his studies, he emphasizes both the need to create good relationships with the upper-class students and the recurring humiliation he experienced when he listened in silence to the insulting comments his friends made in front of him on SC and ST students, and on the quota policy. ${ }^{38}$ While it is impossible to provide the results of a deeper analysis here, we should nonetheless underscore the role Dalit political socialization plays (a type of politicization transmitted within the family or acquired during protest movements on the campus) in the development of a positive identity and relationships of solidarity within the stigmatized group. On this point, our 
own observations agree with the conclusions of the work on the social mobility of individuals from dominated and stigmatized groups (Naudet, 2012).

\section{An unequal return on degrees} students, $52.9 \%$ of SC students and $45.5 \%$ of ST students. These figures are even more telling for the Dual Degree (85.1\% of GENs are registered as against $82.5 \%$ of OBCs, $70.8 \%$ of SCs and $77.8 \%$ of STs) and for the Int MSc ( $65.6 \%$ of GENs are registered with the placement service and only $36.0 \%$ of OBCs, $35.5 \%$ of SCs and $7.1 \%$ of STs). If the SC and ST students (unlike OBC students) have a tendency not to make use of the opportunities provided by the placement office that many students interviewed saw as one of the privileges IITians enjoy, the reasons for this under representation are numerous: on the one hand, the SC/ST students more often follow the path of civil-service examinations, on the other hand, anticipating their low chances of securing a job and/or a good salary in the private sector, they take the initiative to exclude themselves from a service that is reputed for only rewarding the best students. 

and admission status, academic performance (measured by the CPI) and the degree and branch, on the other. Let us begin with a general observation: while $82.8 \%$ of students enrolled in the SPO are placed, $3.9 \%$ of them earn a salary above 25 lakhs (approximately 37,200 US \$) a year; $16,2 \%$ a salary between 11 and 25 lakhs; 37,8 \% a salary between 6,5 and 11 lakhs and $13,3 \%$ a salary lower than 6,5 lakhs. These few elements put the very high figures often provided in the media into perspective (PTI 2014). Indeed, the press often shows an interest in the small minority of students (3,9\% of those registered with the SPO and $4.8 \%$ of students who are placed) who receive offers of over 25 lakhs (approximately 37,200 US \$) per year, ignoring the others. Newspapers rarely mention, for example, that $17.2 \%$ of the students registered with the SPO did not find placements, or that $50 \%$ of the students who were placed by the SPO are paid a salary of only 11 lakhs (16,313 US \$) a year. Or even, as we saw above, that the statistics created on the basis of SPO data, in reality, only involve a larger or smaller proportion of IIT graduates, depending on the streams.

Is there an association between high academic results and high salaries as the meritocratic discourse claims? To start with, the students who found a job had, on average, higher final marks: 7,9 as against 7,2 for those who did not have a job (the range of the marks is from 4,5 to 10 ). The distribution of (CPI) marks by salary level shows that the students who are paid the highest salaries were recruited at the highest academic levels; this is all the more true of students who have a salary of over 25 lakhs. We can clearly see, however, that for each salary level, the range of marks obtained can be quite wide and they overlap. This "slack" between the academic mark and the salary secured for a first job deserves to be questioned in order to see whether it is a result of economic criteria (position within the job market the program leads towards) and/or whether it is related to the individual's social qualities. The general trend seems hence to confirm the meritocratic discourse expressed by the institution, but this is certainly not the only mechanism at work. 


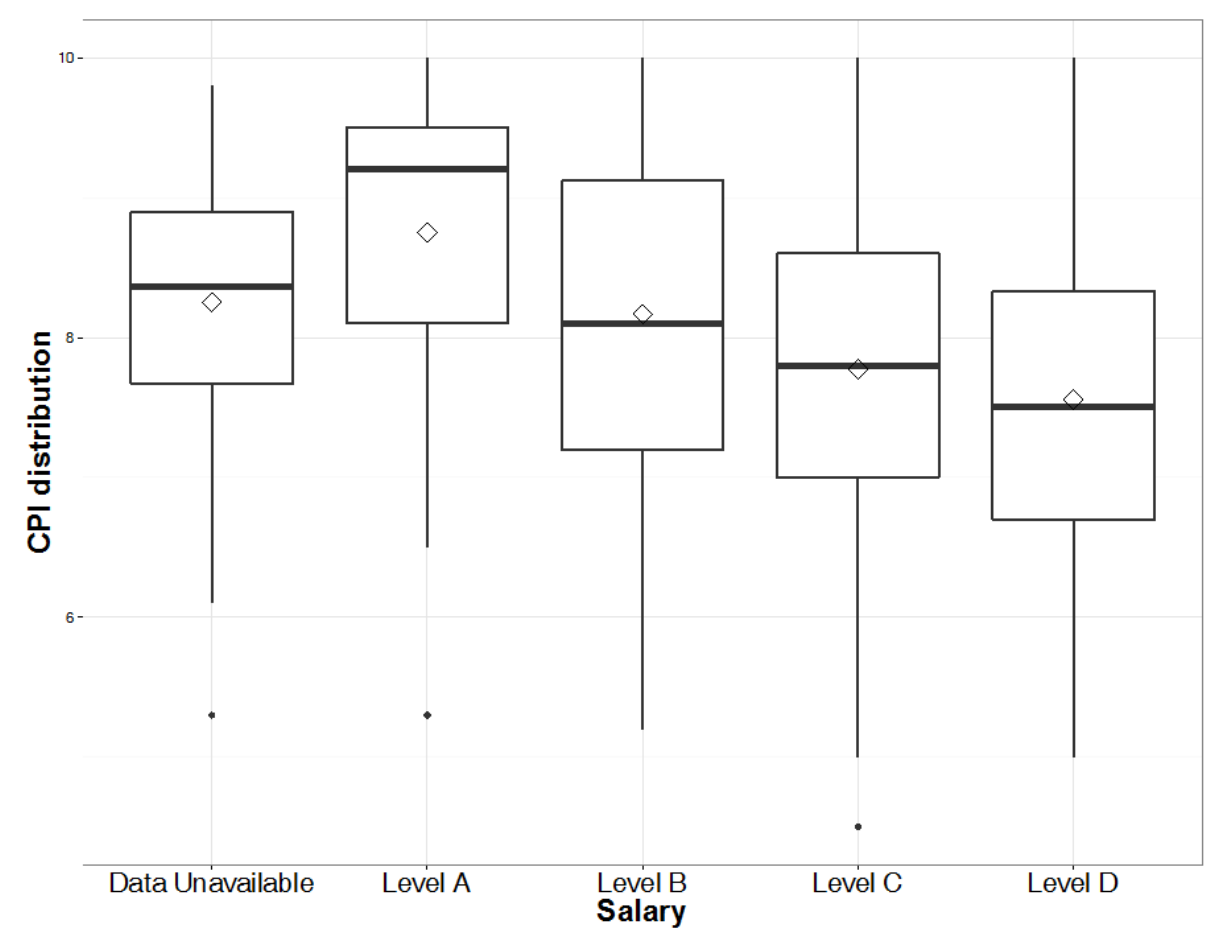

Reading: the boxplots (also known as whisker plots) allow the CPI marks to be distributed (along the ordinate) for each salary level the students secure (on the abscissa). For every salary level (Level A to D), these boxplots provide information about the mark distribution profile. The bold horizontal line represents the median, the one above is the third quartile, the one below is the first quartile, which means that one can very quickly visualize the $\mathrm{CPI}$ interval containing half of the students for a given salary. On each boxplot we have added the average, shown by a dot (Le Guen 2002).

Since students belonging to the reservation quota groups have a lower level of academic achievement, it can be assumed that this will have an impact on their employability and their salaries. The results show that students admitted from the general list more easily find jobs than students admitted on the basis of reserved quotas: $90 \%$ of the GEN students registered with the SPO found a job as against $77 \%$ of the OBCs, $68 \%$ of the SCs and barely $46 \%$ of the STs. Therefore, the hierarchy between groups remains the same, be it for academic performance or finding a job. Since academic achievement seems to partly determine the placement rate on the labor market, it remains to be verified whether for an equal grade, different placement rates are observed for different groups.

We will hence model the probability of finding a job depending on the CPI and the students' status, using a binomial logistic regression. The estimates, translated into probabilities in figure 5, clearly show that with equal marks (CPI) the probabilities of finding a job through the SPO are not equal, and differ according to admission status. While the probability of finding a job increases with an increase in the CPI, students admitted on the general list have greater chances of finding a job than students admitted on quotas. There are also disparities between the different quota groups: OBCs fare relatively better in finding a job than SCs, while STs are those with the lowest employment rates. These results corroborate and support the results of other works that highlight the mental representations shared by those responsible for recruitment at large private firms, which contribute to eliminating candidates from the reserved categories (Jodhka and Newman 2010; Deshpande and Newman, 2010). 
Figure 5 - Predicted probability of securing a job through the SPO by final mark and admission status

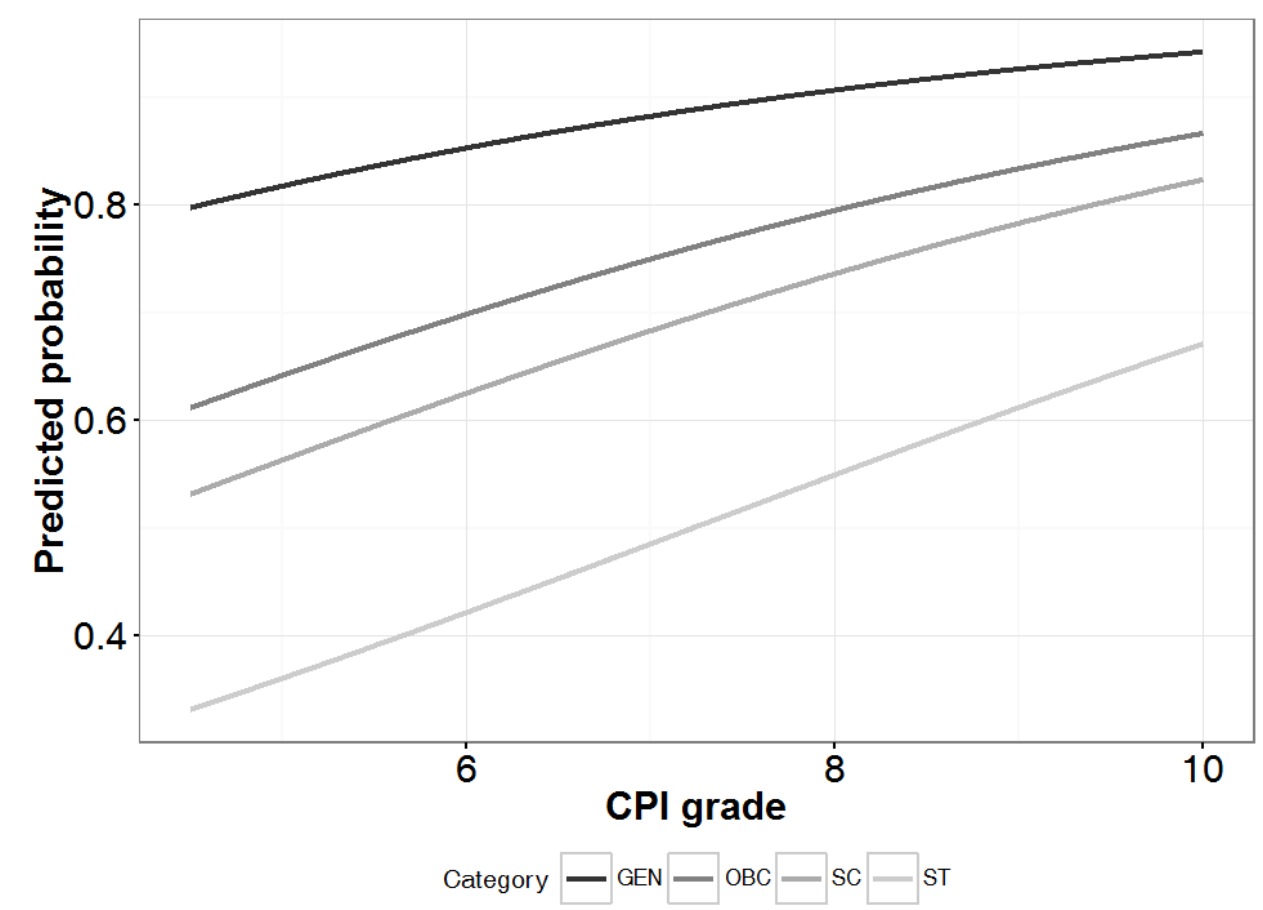

Note: the relationship between the probability of securing a job and the CPI mark is positive. At every mark level the GENs have a higher probability of securing a job than the OBCs, the SCs and the STs.

The predicted probabilities are calculated using the coefficients of the logistic regression, for details of the calculation one can refer to Bressoux, 2014. The coefficients and statistics associated with the regression model appear in table $\mathrm{A} 1$ of the annex.

Cases: All the students registered with the SPO, for whom the information is available.

Beyond these observations on the student placement rate, we can examine the salary differences by admission status group. To do this, we model a multinomial logistic regression performed on the salary levels according to academic success and admission status. ${ }^{41}$ The reference modality of the variable is the probability of securing a salary lower than 6,5 lakhs a year, the estimated regression coefficients are based on the probability of securing a salary between 6,5 and 11 lakhs and a salary above 11 lakhs. ${ }^{42}$ If we look at the marginal effects of the significant logit coefficients, the fact of being an $\mathrm{OBC}$ rather than a GEN decreases the probability of securing a salary between 6,5 and 11 lakhs rather than a salary lower than 6,5 lakhs by almost $12 \%$; (for this salary range, we cannot predict the results for other admission statuses as they are not significant). Above all, being an $\mathrm{OBC}$ rather than a GEN reduces the probability of securing a salary of over 11 lakhs rather than a salary lower than 6,5 lakhs by $26 \%$. For SCs, this probability decreases by $22 \%$ and for STs it decreases by $38 \%$, in relation to the GENs. 
Table 1 - Model of securing an annual salary of above 6.5 lakhs, based on the final CPI and the admission status, among students who secured a job

\begin{tabular}{|c|c|c|c|c|c|c|c|c|}
\hline$\frac{1}{\frac{0}{2}} \frac{0}{\frac{\pi}{2}}$ & \multicolumn{2}{|c|}{$\begin{array}{l}\text { Reference modality } \\
\text { Salary below } 6.5 \\
\text { lakhs/annum }\end{array}$} & \multicolumn{3}{|c|}{$\begin{array}{l}\text { Active modality } \\
\text { Salary between } 6.5 \text { and } 11 \text { lakhs/annum }\end{array}$} & \multicolumn{3}{|c|}{$\begin{array}{l}\text { Active modality } \\
\text { Salary above } \mathbf{1 1} \text { lakhs/annum }\end{array}$} \\
\hline \multirow{6}{*}{ 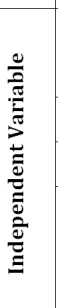 } & $\begin{array}{l}\text { Variable } \\
\text { Reference }\end{array}$ & Modality & $\begin{array}{l}\text { Coefficient (log } \\
\text { odd) }\end{array}$ & $\begin{array}{l}\text { Marginal } \\
\text { effect }\end{array}$ & Significativity & $\begin{array}{l}\text { Coefficient (log } \\
\text { odd) }\end{array}$ & $\begin{array}{l}\text { Marginal } \\
\text { effect }\end{array}$ & Significativity \\
\hline & & Intercept & 1.35 & & $* * *$ & 0.85 & & $* * *$ \\
\hline & CPI (scaled) & & 0.11 & & n.s. & 0.48 & $+9,0 \%$ & $* * *$ \\
\hline & \multirow{3}{*}{$\begin{array}{l}\text { Admission } \\
\text { status } \\
G E N\end{array}$} & $\mathrm{OBC}$ & -0.62 & $-11,9 \%$ & $* * *$ & -1.08 & $-25,8 \%$ & $* * *$ \\
\hline & & SC & -0.37 & & n.s. & \begin{tabular}{|l|}
-0.93 \\
\end{tabular} & $-22,1 \%$ & ** \\
\hline & & ST & -0.47 & & n.s. & -1.59 & $-37,8 \%$ & * \\
\hline
\end{tabular}

Note: The coefficients are shown with the corresponding significance, the stars indicate the degree of statistical significance: * $10 \%, \star \star 5 \%, * \star \star 1 \%$. Non-significant coefficients are noted n.s.

The model is a multinomial logistic regression, where the reference modality of the dependent variable is the fact of securing a salary below 6.5 lakhs a year. The values in the "Marginal effect" column show the predicted variation of the frequency of this modality depending on the different parameters shown in the model. They correspond to a translation of the significant logits into different probabilities and facilitate the reading. For example, the increase of a point in the CPI score increases the probability of securing a salary above 11 lakhs/year by $9 \%$. At the same time, being an OBC reduces this probability by $25,8 \%$

Likelihood ratio test of the model with a single constant: 1,552, in the model with explanatory variables: 1,492. Significant likelihood ratio test at $\mathrm{p}<0.1 \%$.

Cases: All students registered with the SPO, who secured a job, for whom the information is available. distribution, starting from the hypothesis that posits that students from the bestclassified departments in the symbolic hierarchy should, in principle, more easily find better jobs and higher salaries. Can we observe a "stream effect" that would limit or increase social inequality between students?

Unsurprisingly, we note that the three engineering departments at the top of the classification established by the JEE are those with the highest job-placement rates. But if one looks at the other departments, certain questions arise. Thus the Chemical Engineering department's position, where girls are slightly better represented, is surprising: this department occupies a relatively high position in the JEE classification, a rank that does not seem to correspond to the placement opportunities this subject offers, nor to the salary level of the students placed. In addition, the Civil Engineering department recruits students whose JEE results are far higher than those of the students recruited by the Material and Metallurgical Engineering department, but their placement rate is far lower than that of the latter department..$^{43}$ Our analysis of the job placement rates thus only partially confirms the departmental hierarchy, as presented in the JEE ranking: the inconsistencies in the relationship between "titles" and "jobs" seem to be greater for the departments located in the lower half of the hierarchy.

If we now question the connections between the different departments (more or less selective), the scores and the students' admission status, do we find, as the partisans of the mismatch hypothesis claim, that students from minority groups are less successful when they graduate from the more selective departments (Frisancho et al. 2012)? Our data allows us to answer this question from the viewpoint of the job placement rate and 
not from the point of view of the salary secured ${ }^{44}$ which is the only factor economists specializing in the evaluation of Affirmative Action look at.

Our data allows us to state that, regardless of the admission status and the students' score, the job placement rate is higher when they graduate from the more selective departments. ${ }^{45}$ Nonetheless, however selective the department, the inequalities between GEN and minority-group (OBC, SC, ST) students remain. These inequalities are however far more important in the less selective departments (Figure 5). Finally, with equal CPI scores, these inequalities are the most pronounced for the lowest CPI scores in the less selective streams. 46

In other words, with the same score, the fact of graduating from a selective department would provide some amount of protection from inequalities in job placement for students from the minority groups: the differences still exist, but they are reduced. On the contrary, the less selective departments provide better returns for students who do not belong to a minority group: they are more advantageous for upper-class students. Better equipped to take advantage of the less highly-classified streams, these students use other types of capital to compensate for their poor academic results and thus manage to find a place on the job market. This last observation, congruous with the inconsistencies in the relationship between titles and jobs that seem to characterize the less selective departments, thus tends to refute the Mismatch hypothesis. The Int MSc in Economics is an example of the courses located at the bottom of the hierarchy in 2011 that were highly profitable on the job market. We have noted the strong presence of women in the economics course and the recent arrival of SC students who were almost absent from this course when it was first created. It seems that the economics program-as it is new and has relatively less-demanding admission criteria, and for which job prospects are probably not yet stabilized-attracts students predisposed to taking risks and moving away from the core sectors of engineering, in the hope of more easily securing a job and a better salary. ${ }^{47}$ But the return on the qualification is still unequal here, as the proportion of GEN students who find a job is far higher than the proportion of minority group students.

\section{Employment rate by stream selectivity and admission status}

\section{Figure 6a - For all the CPI scores combined}

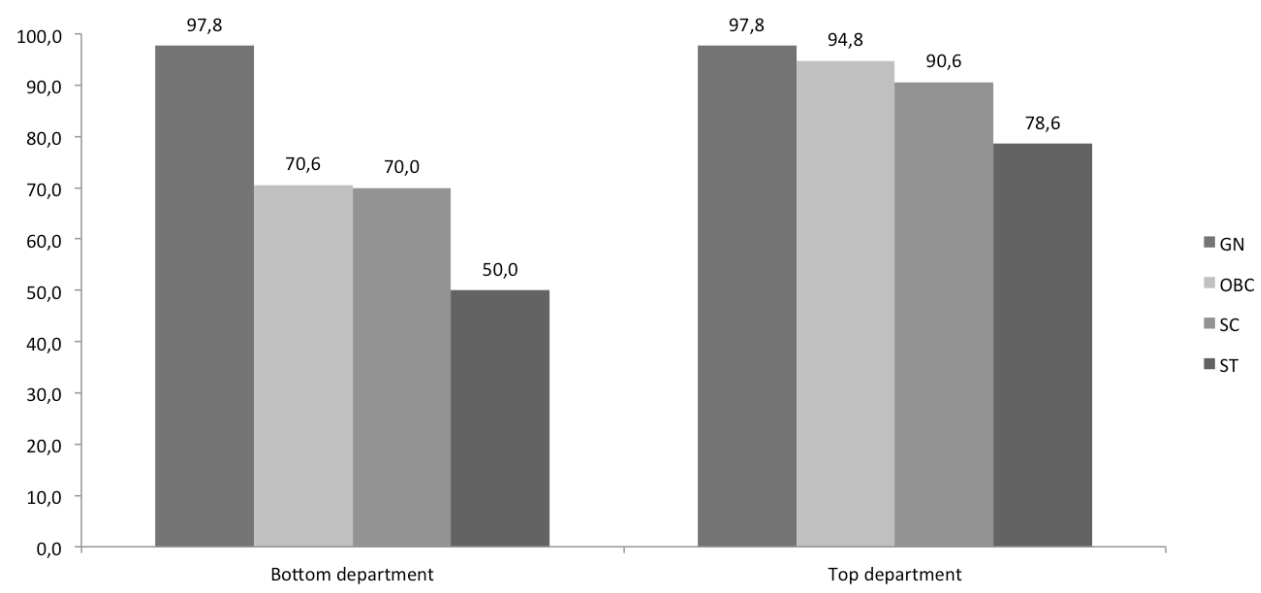


Figure $6 \mathrm{~b}-$ For the lowest scores (CPI lower than 7)

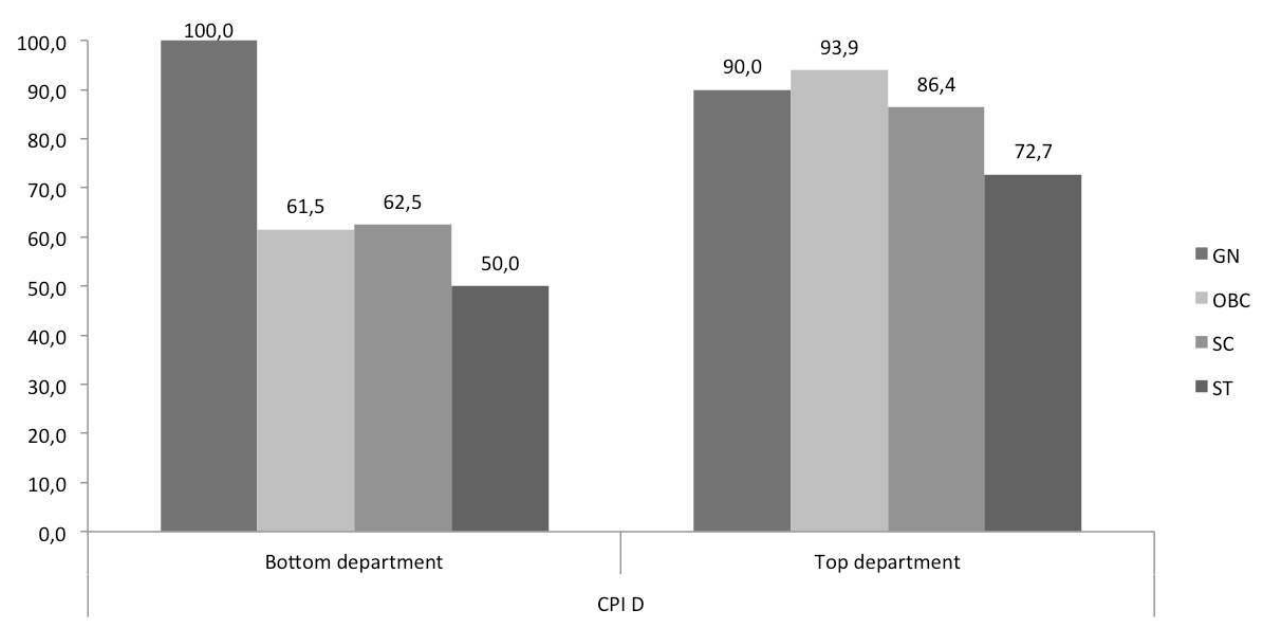

Note: all scores combined, the employment rate is higher in the Top department than in the Bottom department. In addition, for the lowest scores, the inequalities in the employment rates between OBCs, SCs and STs on the one hand, and GENs on the other, are stronger in the Bottom department for the lowest CPIs.

Cases: All students registered with the SPO for whom the information is available.

These findings question the meritocratic principle of direct association between academic achievement and professional success. If one of the criticisms addressed to the quota policy is its lack of meritocracy, since it encourages students whose educational outcomes are lower, we note here that it is the reserved groups that suffer unequal treatment for equal academic success. Social mobility through academic institutions, apparently favored by the quota policy, appears very relative: on graduating from an IIT, the private sector logic, which ignores the reservation policy, prevails. But, to locate the existence the mechanisms that the social value of academic qualifications are based upon outside the institution is to forget that the specific functioning of the academic institution is well adapted to the demands of the private sector and actively contributes to making degrees unequally profitable. Thus the students interviewed emphasized the importance recruiters attach to involvement in the extra-curricular activities the institution offers (cultural activities like music, theatre, poetry, dance, etc., as well as sporting and scientific activities). These extra-curricular investments are seen as so many indicators of the spirit of competition, the capacity to introduce and sell oneself, and above all, of qualities such as "curiosity" and "disinterest"-in short inherited capital. ${ }^{48}$ Now the SC and ST students often mentioned the fact they do not participate in the activities offered by the Gymkhana (the student's body in charge of extra-curricular activities) for a variety of reasons. Some of them are officially excluded due to their poor academic results. Others exclude themselves for various reasons: lack of familiarity with the dominant culture, focus on academic work and under estimation of the importance of extracurricular activities in terms of valorizing the degree, a refusal to yet again occupy a subaltern position by taking part in activities whose leaders are chosen among the best students and all belong to the upper castes. ${ }^{49}$ 


\section{Conclusion}

Contrary to the idea that caste is a rural, traditional institution, ${ }^{50}$ that is to say "marginal" in modern India, we observe that at the highest-level academic institutions for technical elites, it still determines social trajectories. Questioning the meritocratic model promoted by the institution, we have revealed the multiple mechanisms the institution employs to eliminate and sanction students from the dominated groups, particularly SC and ST students, thus contributing to the differential value of the academic titles it delivers. The statistical analyses carried out reveal the mystifying role of the school, as at the end of these selection and segregation processes, students from the upper class seem to be the only legitimate holders of the academic title: "The apparent neutrality of the school enables this to transform social differences into educational differences by passing off properties acquired in the family milieu as 'natural gifts.' In a society where obtaining social privileges depends ever more closely on the possession of educational titles, this ideology of 'gift,' by which those who 'inherit' become those who 'merit,' fills an essential function in legitimizing the social order" (Bourdieu, quoted by Discepolo and Poupeau 2008:33).

Having revealed the school's function of legitimizing the social order our study gives weight, which will be nuanced at a later stage, to a variable admission status constructed by the institution in conformity with its political interests. As we have seen, this category groups together students of very different academic levels and from very different social origins, and these would benefit from being split into a series of indicators showing the position the family occupies in the social class and caste structure. The statistical analysis has nonetheless shown the determining nature of admission status: going against the ideology of the individual gift, it gives students from the dominated group the means to see "their individual destiny as a specific case within a collective destiny" (Bourdieu, quoted by Discepolo and Poupeau 2008:38). At a second stage, as we have attempted to show, it remains necessary to take into account the students' social dispositions and their practical ability to respond to social restrictions, that is to say to go beyond the mechanical aspect of determinism while avoiding the pitfalls of subjectivism.

Figure 2 - Position of the IITL departments in the GEN students JEE classification (first and last student, source: JEE report 2011)

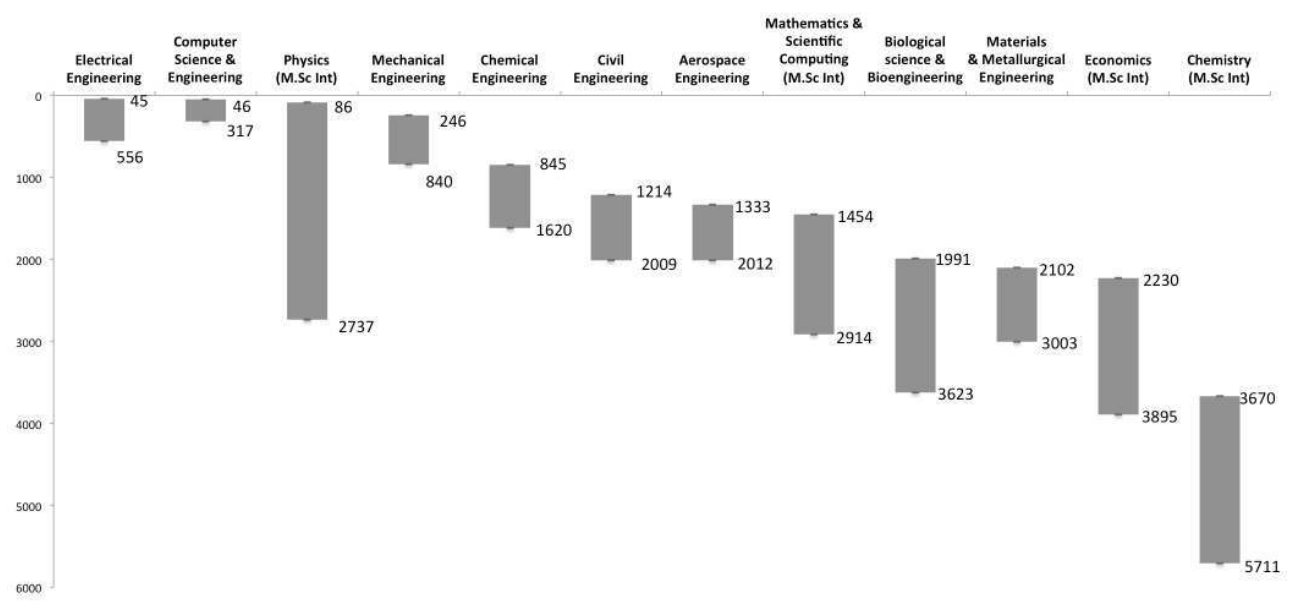




\section{BIBLIOGRAPHY}

Bertrand, Marianne, Rema Hanna and Sendhil Mullainathan. 2010. "Affirmative Action in

Education: Evidence from Engineering College Admissions in India." Journal of Public Economics 94: 16-29.

Bourdieu, Pierre. [1979] 1984. Distinction: A Social Critique of the Judgement of Taste. Translated by R. Nice. Cambridge: Harvard University Press.

Bourdieu, Pierre. [1989] 1996. The State Nobility: Elite Schools in the Field of Power. Translated by L.C. Clough. Cambridge: Polity Press.

Bourdieu, Pierre. [2001] 2004. Science of Science and Reflexivity. Translated by R. Nice. Chicago, Cambridge: University of Chicago Press, Polity Press.

Bressoux, Pascal. [2010] 2014. Modélisation statistique appliquée aux sciences sociales. Paris: De Boeck.

Dalit Media Network Chennai. 2001. "Dalits at the Indian Institutes of Technology." People's Union for Civil Liberties (PUCL) Bulletin, Madras. http://www.pucl.org/reports/National/2001/ dalits.htm

Deauvieau, Jérôme. 2010. "Is It Possible and Desirable to Translate a Logit Coefficient into Probabilities? Reply to Comments by Marion Selz on My BMS 2010 Article." Bulletin of Sociological Methodology 112(1): 32-42.

Deshpande, Aswini and Katherine S. Newman. 2010. "Where the Path Leads: The Role of Caste in Post-University Employment Expectations.” Pp. 88-122 in Blocked by Caste: Economic Discrimination in Modern India, edited by S. Thorat and K. S. Newman. Delhi: Oxford University Press.

Deshpande, Ashwini. 2011. The Grammar of Caste: Economic Discrimination in Contemporary India. Oxford: Oxford University Press.

Deshpande, Satish. 2013. "Caste and Casteless. Toward a Biography of the "General Category." Economic \& Political Weekly 48(15): 32-39.

Discepolo Thierry and Franck Poupeau, eds. 2008. Political Interventions: Social Science and Political Action. Translated by D. Fernbach. London, New York: Verso.

Elias, Norbert and John L. Scotson. 1965. The Established and the Outsiders: A Sociological Enquiry into Community Problems. London: Frank Cass and Co ltd.

Frisancho, Veronica, C. Robles and Kala Krishna. 2012. "Affirmative Action in Higher Education in India: Targeting, Catch Up, and Mismatch at IIT-Delhi." NBER Working Paper Series. Retrieved July 6, 2016 (http://www.nber.org/papers/w17727).

Headley, Zoé. 2013. "Caste et ordre social en Inde contemporaine.” Pp. 19-36 in Justifier l'ordre social, edited by C. Jaffrelot and J. Naudet. Paris: PUF.

Jaffrelot, Christophe. 2015. "Patels and the Neo-middle Class Syndrome." The Indian Express, August 27. (http://indianexpress.com/article/opinion/columns/patels-and-the-neo-middleclass-syndrome/).

Jaffrelot, Christophe. 2013. "Partir de la caste pour penser les assignations identitaires." Pp. 5-17 in Justifier l'ordre social, edited by C. Jaffrelot and J. Naudet. Paris: PUF. 
Jodhka, Surinder and Katherine S. Newman. 2010. "In the Name of Globalization: Meritocracy, Productivity, and the Hidden Language of Caste." Pp. 52-87 in Blocked by Caste: Economic Discrimination in Modern India, edited by S. Thorat and K. S. Newman. Delhi: Oxford University Press.

Kelkar, Shreeharsh. 2013. “The Elite's Last Stand: Negotiating Toughness and Fairness in the IITJEE, 1990-2005.” Working paper. Retrieved July 6, 2016 (http://web.mit.edu/skelkar/www/ shreeharsh-kelkar_files/Kelkar-IIT_JEE_ver4.pdf).

King, A. D. 1970. “The IIT Graduate 1970: Aspirations, Expectations and Ambitions.” Economic \& Political Weekly 5(36): 1497-510.

Kumar, Anoop. 2011, “Caste Discrimination in IIT Delhi: A Report.” May 1. https:// thedeathofmeritinindia.wordpress.com/2011/05/01/caste-discrimination-in-iit-delhi-a-report/

Kumar, Krishna. 1985. "Reproduction or Change? Education and Elites in India." Economic \& Political Weekly 20(30): 1280-84.

Kumar, Neelam, ed. 2008. Gender and Science: Studies across Cultures. Delhi: Cambridge University Press India.

Lardinois, Roland. 1985. "Les luttes de classement en Inde." Actes de la recherche en sciences sociales 59: 78-83.

Lardinois, Roland. 2014. "Le secteur des technologies de l'information et de la communication en Inde." Les études de l'emploi Cadre, 07.

Le Guen, Monique. 2002. "La boîte à Moustaches pour sensibiliser à la statistique." Bulletin de Méthodologie Sociologique: 43-64.

Mandal, Dilip C., Anoop Kumar, Gurinder Azad, Nidhin Shobhana and Shefali Saini. 2015.

"Excellence" through Expulsion: A case of Arbitrary Merit vs Constitutional Mandate, Fact finding report, 62p.

Nair, Sreelekha. 2012. "Women in Indian Engineering: A Preliminary Analysis of Data from the Graduate Level Engineering Field in Kerala and Rajasthan.” Occasional Paper. Centre for Women's Development Studies 58.

Naudet, Jules. 2012. Entrer dans l'élite. Parcours de réussite en France, aux États-Unis et en Inde. Paris: PUF.

PTI. 2014. “12 IIT Kanpur Students Get Whopping Rs $1 \mathrm{cr}$ Salary Package.” The Indian Express, January 10 (http://indianexpress.com/article/india/india-others/12-iit-kanpur-students-getwhopping-rs-1-cr-salary-package/).

Rajagopalan, C. and Jaspal Singh. 1968. "The Indian Institute of Technology: Do They Contribute to Social Mobility?" Economic \& Political Weekly 3(14): 565-570.

Srinivas, M. N. 1952. Religion and Society amongst the Coorgs of South India. Oxford: Clarendon Press. Subramanian, Ajantha. 2015. "Making Merit: The Indian Institutes of Technology and the Social Life of Caste." Comparative Studies in Society and History 57(2): 291-322.

Varma, Roli and Deepak Kapur. 2009. "Access, Satisfaction, and Future: Undergraduate Education at the Indian Institutes of Technology." Higher Education 59(6):703-17. 


\section{NOTES}

1. This research is a part of the ENGIND programme, funded by the ANR.

2. Scheduled Castes' (SCs) is a category created at the beginning of the 20th century, and "Scheduled Tribes" (STs) gained national administrative status just after independence. In the public administrative services and government universities in India, 15\% of seats are reserved for SCs and $7.5 \%$ for STs.

3. After very long and lively controversies from Independence until the publication of the Mandal Commission conclusions in 1990, the Congress party agreed to extend the OBC (other groups are also called "backward," but they occupy very different social positions) reservation policy to include universities in 2007. The decision was suspended by the Supreme Court for lack of statistical data (the last population census that systematically recorded the cast variable, dates from 1931). A year later this policy was implemented on condition that higher-education establishments increase their student capacity by $54 \%$. On this point see Jaffrelot (2013). These controversies are far from over as recent Indian news proves, with the Patel movement in Gujarat in the summer of 2015 or more recently the Bihar state elections in which reservation policies played an important role (Jaffrelot 2015).

4. The undergraduate program selects students after class 12 on the basis of a national examination, the JEE, which, as we will see, would like to be seen as the embodiment of meritocratic values.

5. For the IIT studied, the annual number of graduates has increased from 71 in 1965 (first class year) to 1273 in 2014 (last year taken into account for our study).

6. This IIT, which we will call IITL, is one of the oldest, and is one of the "top 7" IITs today.

7. Gathering this data was a long and sometimes arduous process: we had to identify the right interlocutors, convince them of the relevance of our questions, and little by little win them over. We would like to thank all of them here.

8. Castes, as administrative categories, have been built following two hierarchical principles (the ritual/symbolic status and the socio-economic status) that were the object of very old debates and do not completely overlap (Lardinois 1985). See Headley (2013) on the polysemy of the term "caste," which has been the focus of social struggles and arbitrary administrative divisions.

9. According to the data available in the Report of the Joint Implementation Committee (IIT Kharagpur, August 2014), about 1 million 200,000 students register for the JEE after class 12. 600,000 pass the main JEE and 100,000 are allowed to sit the JEE advanced exam. In the end, 10,000 students pass the JEE advanced exam and will join one of the 17 IITs. On the JEE, see Kelkar (2013) and his ongoing research.

10. A few students from dominated castes choose not to make use of their certificate when they register for the examination and are qualified on the CML.

11. All the students on this CML must have scored at least $10 \%$ on each of the written tests and have obtained an aggregate score of $35 \%$

12. The historical processes over the course of which this regulation was developed, then reified in a computerized programme, deserve to be further explored.

13. Over the last few years in India there has been an increase in economic studies dealing with the relationship between economic growth, social disparity and discrimination (Deshpande 2011). These studies, encouraged by international institutions that finance research, and carried out thanks to partnerships between Indian and American research institutes, are highly influenced by the research problems developed in the United States, on the relationship between social mobility (often reduced to economic income) and racial identity. The single competitive examination system, the JEE, provides an appreciable scientific opportunity for these studies. 
Dealing with IITs or Indian engineering colleges, these studies tend to test the hypotheses most commonly mobilized in scholarly debates on the evaluation of Affirmative Action in the US, from within the Indian higher education system (Bertrand, Hanna and Mullainathan 2010; Frisancho, Robles and Krishna 2012).

14. "Our point estimates also suggest that affirmative action programs come at an absolute cost, because the negative income level effect experienced by displaced upper-caste applicants is far greater than the positive income level effect experienced by displacing lower-caste students." (Bertrand et al. 2010).

15. Interview conducted by Odile Henry, October 2015, IITL.

16. The oldest IITs are considered more prestigious and Kharagpur, Bombay, Kanpur, Madras, Delhi, Guwahati, Roorkee are generally seen as the top 7. In IITL terminology, stream means both the degree (sometimes also called "program"), and the branch of knowledge, or the subject studied. At IITL, each branch is represented in one and only one department.

17. Although not all the qualifying students are admitted, paradoxically there are vacant places. In 2011, the seats reserved for OBCs that remained vacant (there were fewer OBC students whose score was above $-10 \%$ of the cut-off, than seats available) were reattributed to qualifying GENs; this represented 436 seats. With regard to the SCs, all the reserved seats were offered and filled. However, given that the number of ST candidates whose scores were above $-50 \%$ of the cut-off was lower than the number of seats reserved for this category, these vacant seats were converted to seats for preparatory classes, which allowed the students to join an IIT the following year if their academic achievement was sufficient.

18. Figures calculated from the JEE Report 2011.

19. Data from previous years that cross-checks results obtained on the JEE and allocation of students by branch and IITs are available on the JEE website.

20. Three departments are located at the top of the rating and they are all engineering programmes: Computer Science Engineering, Electrical Engineering and Mechanical Engineering. These departments show the best results in terms of job placement after graduation. Then, we have the departments of Physics, Chemical Engineering, Aerospace and Civil Engineering. Lastly, three scientific departments (Mathematics \& Scientific Computing, Economics, Chemistry) are situated at the bottom of the classification, along with two engineering departments: Biological Science \& Bioengineering and Materials \& Metallurgical Engineering. Cf. Figure 2 in annexe.

21. We must note that the Civil Engineering programs recruit SC and particularly ST students, who are ranked far higher than the students they recruit from the general list. While we must question this association, it could be related to the quota policy as applied by the administration.

22. The SC and ST students' unwillingness to join scientific programmes that lead to a PhD can be related to the financial investment this type of course demands. Indeed studies carried out by economists show that, while the income of families of low-caste students admitted on the reservation quotas (displacing groups) are on average four times higher than the average revenue of their caste, this income remains much lower than that of the families of the displaced groups (Bertrand et al. 2010; Frisancho et al. 2012).

23. Even though the figures are not strictly comparable, these percentages are lower than those indicated by the national figures: in 2000 , girls represent $16.2 \%$ of all students in the field of higher education in engineering, according to Kumar and Neelam's (2008) figures (in Nair 2012). The percentage seems even lower when compared with $40.7 \%$ of girls enrolled in 2007 in one of the 194 engineering colleges in Kerala, figures from the Annual Technical Education Reviews (ATER) of Nodal Centre, Kerala, NTMIS, IAMR (in Nair 2012).

24. This is far less true of the postgraduate program: in 2014, only $38 \%$ of the MTech program students and $26 \%$ of the $\mathrm{PhD}$ program students were accepted under the quota system. For these degrees almost all the OBC quota seats were filled, which is far from the case for the SCs and STs. Unlike admission to an undergraduate program (through the JEE), admission to a Master's or a 
$\mathrm{PhD}$ includes an interview. Interviews conducted with teachers and students reveal that SC and ST students tend to be eliminated during this oral evaluation.

25. We have this indicator for the 1,090 students registered with the placement service in 2015 . The analyses of CPI distribution hence concern all these students and include both undergraduates and post graduates.

26. Anoop Kumar (2011) estimates that every year, the SC/ST communities lose an average of $62 \%$ of the seats attributed to them at IITS for various reasons such as unfilled seats, expulsion, drop out and suicide.

27. The horizontal axis shows the projection of the grade spread and the vertical axis represents the proportion of students around each CPI level.

28. The departments transmit this list of students who are experiencing educational difficulties to the Counseling service that then summons them for a meeting.

29. Some students from poor families have never owned a computer before joining IIT.

30. "In this system, individual students are marked on the basis of the performance of the entire class. For example, if the class on an average scores 75/100, 75 is held as 6.5 CGPA (CPI). Students scoring less than 75 are assigned grade points as per their relative distance from the average marks of the class ... given that there is relative marking hence there would always be a few students who would fall in the category of below 5 every year, irrespective of how hard they work. Every year the lowest ranking students would be kicked out of the institution" (Mandal et al. 2015:33 and 45).

31. There are special funds (the Scheduled Caste Sub Plan and Scheduled Tribe Sub Plan) dedicated to improving the well-being of SC and ST students. In 2015-2016, 450 crores were allocated to the IITs (Mandal et al. 2015).

32. The students have two years to to clear their backlog. Beyond this deadline they have to pay a fee of 45,000 INR (appproximately 660 US \$) for each test they retake (Mandal et al. 2015).

33. "One of the students recollected his experience with an upper-caste senior. When he approached this senior with a doubt the senior remarked that 'being an ST he would not understand the concept"' (Mandal and al. 2015:37).

34. Nearly $95 \%$ of the 427 faculty positions in IIT Madras were occupied by the Hindu "upper castes" in 2001 (Dalit Media Network 2001).

35. See Elias and Scotson (1965). These concepts seem to be particularly useful for a sociological understanding of these realities. Thus the charismatic group (constructed according to the model of the minority of the best) is the one that manages to impress upon the members of the stigmatized group the highly valorised image it has of itself, while the stigmatized group (constructed on the basis of the minority of the worst) is the one that is given its debased image, which is then progressively internalized, by others (the members of the charismatic group): the members of a stigmatized group tend to see themselves through the eyes of the dominant.

36. A questionnaire that seeks to objectivize the structure of the social relationships between the students was created and was to be distributed to all the students belonging to a Btech class year at IITL. Unfortunately, in the end, we were refused permission to distribute this questionnaire.

37. Other elements come into play-for example the very strong family pressure to marry and have children-that place girls in an ambiguous positon as they are better represented in the longer programs and are subject to strong pressure to study for a limited time. There is also the fact they manage to build support circles in the scientific program where they are a minority.

38. "If you stop making friends with them it will be hard for you. So I accepted this fact, even though they are saying bad things about SC, ST," Interview with Amit, conducted by Odile Henry, JNU, Delhi, May 2016.

39. We compared the SPO figures with the student numbers of the final year for each program of the undergraduate program (BTech, BSc, Dual Degree and Int MSc) based on the "roll list." 
40. It is impossible to obtain precise information about the trajectories of students who are not registered at the SPO since the departments do not systematically collect data on their alumni.

41. A more parsimonious ordinal logistic regression model was tested but the parallel lines hypothesis was violated both by the test score and visually.

42. The salary brackets between 11 and 25 lakhs and above 25 lakhs were grouped due to the sample size.

43. This discrepancy between a relatively high level of academic success in the JEE and a low placement rate is also true of students recruited by the Aerospace department.

44. Our results do not show any evidence of a department effect on salary inequalities, except for the highest salaries in the most selective departments, most often allocated to GEN students.

45. "More selective departments" include the three top departments of the JEE 2011: Electrical Engineering, Computer Science Engineering and Mechanical Engineering. "Less selective departments" include the departments of Mathematics, Biological Science and Engineering, Economics, Material \& Metallurgical Engineering and Chemistry (see figure 2 in annexe). The SPO data for placement in 2014-2015 correspond to Btech students admitted through the JEE 2011.

46. Taking into account the low number of students with a high CPI, we cannot generalize this observation for all CPI slabs.

47. This observation contradicts the so-called risk aversion mentioned in some studies to explain that students from minority groups are not represented in the "Winning Jobs" category (Frisancho et al. 2012).

48. Thus, a survey of 25 human-resources directors working for large Indian companies shows that, although they constantly employ the rhetoric of merit, recruiters attach great importance to the candidates' social background. Their individual properties are never clearly separated from those of the family, and beyond this, the community (Jodhka and Newman 2010).

49. At IITL, the person in charge of the class is the one who has the best marks. AT IIT Roorke, an internal rule stipulates that the candidate who stands for the position of President of the Students' Affairs Council has to have a CPI above 7.5 and only students whose CPI is higher than 6.5 can manage cultural events like the festivals and other shows the IIT organizes. (Mandal et al., 2015).

50. Some students admit there are forms of discrimination on the campus against students admitted on the quota basis and GEN students from rural areas, who are considered "backward," are singled out.

\section{ABSTRACTS}

Exempted from the application of reservation policies at first, the Indian Institutes of Technology tend to be perceived as institutions that produce a meritocratic elite, freed from the contingencies related to caste and their political exploitation. However, some former students, products of this institution that was marked by a very strong social homogeneity when it was first conceived, see the introduction of quotas for the Scheduled Castes (SC) and Scheduled Tribes (ST) in 1973, then a new category of reservations for the Other Backward Castes (OBCs) in 2008, as a threat to the meritocratic spirit of the IITs. They believe the "marked down" admission of these new students has weakened the IIT "brand." Based on fieldwork in one of these elite technical education institutions, we will question this meritocratic model. We will highlight the processes 
by which the IITs continually and differentially eliminate students from the dominated groups (in particular those belonging to the SC and ST categories), and contribute to a high differentiation in the return on, hence the social value of, educational titles on the job market.

INDEX

Keywords: engineering, elites, meritocracy, education system, social reproduction, reservation policies

\section{AUTHORS}

\section{ODILE HENRY}

Professor, Political Science Department, Université Paris 8

\section{MATHIEU FERRY}

Graduate Student, ENS Cachan 